Supplementary Information

\title{
Human dermal fibroblast viability and adhesion on nanocellulose coatings: influence of surface characteristics
}

Ruut Kummala ${ }^{\dagger}$, Diosángeles Soto Véliz ${ }^{\dagger}$, Zhiqiang Fang§ ${ }^{\S}$ Wenyang Xu ${ }^{\dagger}$, Tiffany Abitbol $^{¥}$, Chunlin $\mathrm{Xu}^{\dagger}$, Martti Toivakka ${ }^{\dagger^{*}}$

†Laboratory of Natural Materials Technology, Åbo Akademi University, 20540 Turku, Finland

${ }^{\S}$ State Key Laboratory of Pulp and Paper Engineering, South China University of Technology, Guangzhou 510640 Guangdong, People’s Republic of China

${ }^{¥}$ RISE, Research Institute of Sweden, Drottning Kristinas väg 61, 11428 Stockholm, Sweden

*correspondence to: martti.toivakka@abo.fi

Other Supplementary Materials for this manuscript includes the following:

VinculinPipeline.cppipe 


\section{Extended cellulose nanomaterial preparation methods}

\section{Table S1}

Summary of CN manufacture information and abbreviations.

\begin{tabular}{llll}
\hline Abbreviation & Sample & Cellulose origin & Processing steps \\
\hline MFC & $\begin{array}{l}\text { Microfibrillated } \\
\text { cellulose }\end{array}$ & Bleached softwood & $\begin{array}{l}\text { Mechanical treatment using a } \\
\text { refiner equipped with } \\
\text { specialised plates }\end{array}$ \\
\hline CNF_L & $\begin{array}{l}\text { Low degree of } \\
\text { TEMPO-mediated } \\
\text { oxidation of cellulose } \\
\text { nanofibres }\end{array}$ & Bleached softwood & $\begin{array}{l}\text { TEMPO-mediated oxidation, } \\
\text { centrifugation, filtration, high- } \\
\text { pressure homogenization }\end{array}$ \\
\hline CNF_M & $\begin{array}{l}\text { High degree of } \\
\text { TEMPO-mediated } \\
\text { oxidation of cellulose } \\
\text { nanofibres }\end{array}$ & $\begin{array}{l}\text { Bleached hardwood } \\
\text { Kraft fibres }\end{array}$ & $\begin{array}{l}\text { TEMPO-mediated oxidation, } \\
\text { centrifugation, filtration, high- } \\
\text { pressure homogenization }\end{array}$ \\
\hline CNC & Cellulose nanocrystals & $\begin{array}{l}\text { Cotton fibres } \\
\text { (Whatman ashless } \\
\text { filter aids) }\end{array}$ & $\begin{array}{l}\text { Sulfuric acid hydrolysis, } \\
\text { sonication }\end{array}$ \\
& & & \\
\hline
\end{tabular}

\section{$\underline{\text { TEMPO-oxidization of nanocellulose suspensions }}$}

$40 \mathrm{~g}$ bleached kraft hardwood fibres were dispersed in $2000 \mathrm{~mL}$ deionised water including $0.625 \mathrm{~g}$ TEMPO and $4.1156 \mathrm{~g} \mathrm{NaBr}$ (equal to $0.1 \mathrm{mmol}$ and $1 \mathrm{mmol}$ per gram of dry fibre respectively). The obtained suspension was stirred at a speed of $500 \mathrm{r} / \mathrm{min}$ for $10 \mathrm{~min}$. After that, $298 \mathrm{~g} \mathrm{NaClO}$ with $8 \mathrm{wt} \%$ concentration (equals to $8 \mathrm{mmol} \mathrm{NaClO}$ per dry fiber) was added into above suspension at room temperature $\left(27^{\circ} \mathrm{C}\right)$ in a stepwise manner to initiate the oxidation reaction. The $\mathrm{pH}$ was maintained at 10 10.5 during the whole reaction procedure by dropping $2 \mathrm{M} \mathrm{NaOH}$ solution. When the $\mathrm{pH}$ of the suspension was consistent, the modified wood fibres were washed by deionised water for several times to remove the residual chemicals. Finally, fibres were nanofibrillated by passing through a D8 nozzle of a nanofluid homogeniser under 10000 PSI pressure two 
times, and a gel-like Tempo-oxidised cellulose nanofiber (CNF) suspension with a concentration of $1 \mathrm{wt}-\%$ was obtained. A similar procedure was used to produce CNF_L from bleached softwood kraft fibres. Except $5 \mathrm{mmol} / \mathrm{g}$ of $\mathrm{NaClO}$ was used instead of 8 $\mathrm{mmol} / \mathrm{g}$.

\section{Table S2}

Summary of fibrils surface charges and sizes.

\begin{tabular}{l|lllll}
\hline Sample & $\begin{array}{l}\text { Total charge } \\
(\mathbf{m m o l} / \mathbf{g})\end{array}$ & $\begin{array}{l}\text { Fibril diameter } \\
(\mathbf{n m})\end{array}$ & $\begin{array}{l}\text { Fibril } \\
\mathbf{( n m )}\end{array}$ & length & AR $^{*}$ \\
\hline MFC & $0.12 \pm 0.02$ & $\begin{array}{l}8 \mathrm{~nm}-\text { few } \mu \mathrm{m} \\
\text { thick fibril } \\
\text { bundles }\end{array}$ & $\begin{array}{l}600 \mathrm{~nm} \text { to few mm } \\
\text { long fibril bundles }\end{array}$ & - \\
\hline CNF_L & $1.14 \pm 0.04$ & $3.6 \pm 0.7$ & $624 \pm 244$ & 173 \\
\hline CNF_M & $1.50 \pm 0.03$ & $4.7 \pm 1.0$ & $352 \pm 134$ & 75 \\
\hline CNC & $0.25 \pm 0.01$ & $9.6 \pm 3.2$ & $115 \pm 52$ & 12 \\
\hline
\end{tabular}




\section{Extended immunofluorescence staining and image processing}

methods

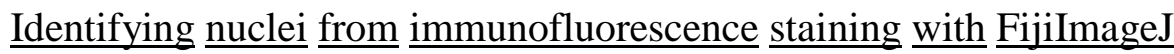

1. Open images acquired from DAPI staining.

2. Adjust brightness/contrast $>$ Auto.

3. Z project $>$ Max intensity.

4. Substract background > Sliding paraboloid 500 pixels.

5. Median > Radius 5.

6. Threshold $>$ Minimum dark.

7. Binary > Fill Holes.

8. Watershed.

9. Analyse particles > Add to manager.

The outlines were verified from each image before summarising the data. Whenever necessary, for example, where segmentation was inefficient or the film was defective (cracks), nuclei were manually counted.

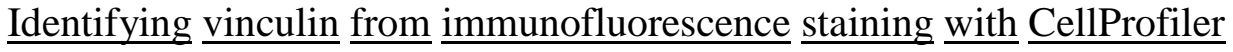

1. EnhanceOrSuppressFeatures to enhance vinculin staining using maximum projection as input file.

2. IdentifyPrimaryObjects to identify vinculin outlines.

3. MeasureObjectSizeShape to describe segmented areas.

4. ExportToSpreadsheet to export measured data.

5. OverlayOutlines to display outlines on the original image.

6. SaveImages to save overlay image file.

The outlines of vinculin were verified from each image before summarising the data. The values obtained per image were divided by the amount of cells in the image (from nuclei) 
to calculate the vinculin outlines per cell. The exact pipeline for CellProfiler ${ }^{\mathrm{TM}}$ is attached as 'VinculinPipeline.cppipe'.

\section{Table S3}

Material specifications for immunofluorescence staining.

\begin{tabular}{|l|l|l|l|l|l|}
\hline Material & Type & Dilution & Host & Catalog & Supplier \\
\hline Anti-Vimentin & Primary antibody & $1: 2000$ & Chicken & 919101 & BioLegend \\
\hline Anti-Vinculin & Primary antibody & $1: 70$ & Rabbit & Ab129002 & AbCam \\
\hline $\begin{array}{l}\text { Anti-Chicken, } \\
\text { Alexa Fluor }\end{array}$ & $\begin{array}{l}\text { Secondary } \\
\text { antibody }\end{array}$ & $1: 2000$ & Goat & A-11039 & $\begin{array}{l}\text { ThermoFisher } \\
\text { Scientific }\end{array}$ \\
\hline $\begin{array}{l}\text { Anti-Rabbit, } \\
\text { Alexa Fluor }{ }^{\circledR} \\
\text { 555 }\end{array}$ & $\begin{array}{l}\text { Secondary } \\
\text { antibody }\end{array}$ & $1: 70$ & Goat & A-32732 & $\begin{array}{l}\text { ThermoFisher } \\
\text { Scientific }\end{array}$ \\
\hline Alexa Fluor
\end{tabular}




\section{Figure S1}

Summary of immunofluorescence staining after one day of cell culture on plant-based nanocellulose coatings. a) Representative images of fibroblast adhesion to LTX, MFC, CNF_L, CNF_M, and CNC. The images include vimentin and actin staining for the cell seeding densities 6000, 13000, and $19000 \mathrm{cells} / \mathrm{cm}^{2}$.

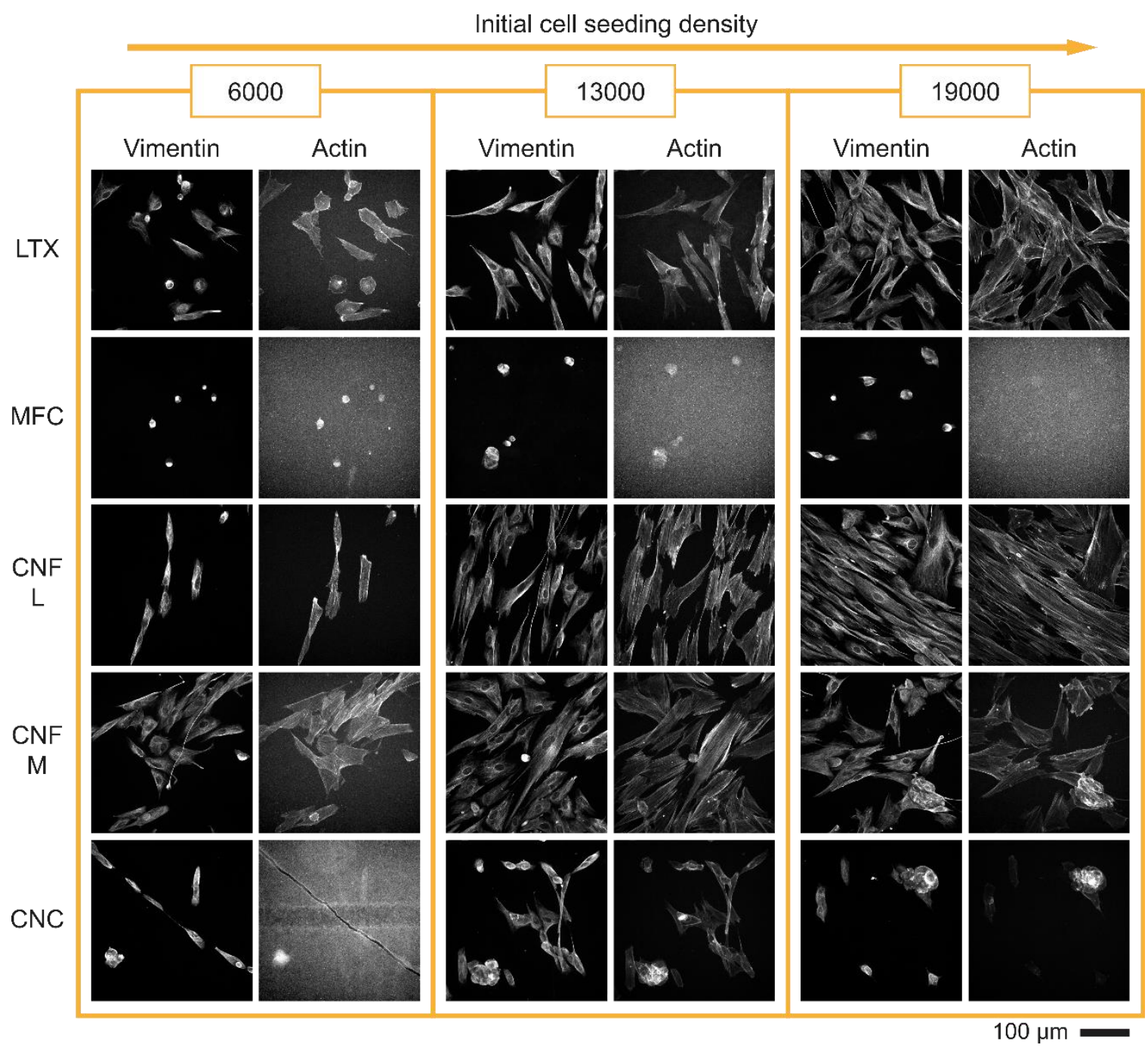

VinculinPipeline.cppipe

File containing the pipeline used to identify vinculin in the immunofluorescence staining. 